\title{
ANALISIS PENGGUNAAN OBAT GASTROESOPHAGEAL REFLUX DISEASE (GERD) PADA PASIEN RAWAT JALAN DI RUMAH SAKIT UMUM DAERAH KARAWANG
}

\author{
${ }^{1}$ Dedy Friyanto, ${ }^{2}$ Siti Lestari \\ ${ }^{1}$ Prodi Farmasi Fakultas Teknologi dan Ilmu Komputer Universitas Buana \\ Perjuangan Karawang (dedyfriyanto@ubpkarawang.ac.id) \\ ${ }^{2}$ Prodi Farmasi Fakultas Teknologi dan Ilmu Komputer Universitas Buana \\ Perjuangan Karawang (fm15.Sitilestari@mhs.ubpkarawang.ac.id)
}

\begin{abstract}
ABSTRAK
Gastroesophageal Reflux Disease (GERD) adalah suatu kondisi refluksnya HCL dari gaster ke esofagus, mengakibatkan gejala klinis dan komplikasi yang menurunkan kualitas hidup seseorang. Angka pravalensi di Indonesia dari tahun ke tahun meningkat yaitu sebanyak $25,18 \%$ pada tahun 2002, peningkatan ini terjadi akibat adanya perubahan gaya hidup yang dapat meningkatkan faktor risiko GERD seperti merokok dan minum kopi. Penelitian ini menggunakan rancangan penelitian analis kuantitatif untuk mengetahui angka kejadian, kerasionalan penggunaan obat dan faktor hubungan penyakit sedangkan kualitatif untuk mengetahui gambaran pola penggunaan obat dan karateristik pasien GERD dengan metode observasional. Hasil penelitian angka kejadian GERD di RSUD Karawang adalah 68 pasien, pada pasien perempuan lebih tinggi sebesar 51,5\% (35 pasien) dan Kerasionalan terapi pada pasien GERD di RSUD Karawang menggunakan tiga literatur yaitu Pharmacotherapy Handbook, British National Formulary edition 70 dan Konsensus GERD di Indonesia edisi tahun 2013 diperoleh hasil rata-rata: tepat indikasi sebesar 80,4\%, tepat obat sebesar $59,3 \%$, tepat pasien sebesar $89,7 \%$ dan tepat dosis sebesar $64 \%$. Pada analisis bivariat menggunakan analisis Kruskal Wallis nilai $p$ sebesar 0,014 menunjukkan jenis kelamin adalah faktor resiko tanda dan gejala Gastroesophageal Reflux Disease (GERD).
\end{abstract}

Kata Kunci : Gastroesophageal Reflux Disease (GERD), Prevalensi, Rasionalitas terapi, Pasien Rawat Jalan.

\begin{abstract}
Gastroesophageal Reflux Disease (GERD) is a condition of HCL reflux from gastric to esophagus, resulting in clinical symptoms and complications that reduce a person's quality of life. The pravalence rate in Indonesia has increased from year to year by as much as $25.18 \%$ in 2002 , this increase is due to lifestyle changes that can increase GERD risk factors such as smoking and drinking coffee. This study uses a quantitative analyst research design to determine the incidence, rational use of drugs and disease relationship factors while qualitative to describe the pattern of drug use and characteristics of GERD patients with observational methods. The results of the study of the incidence of GERD in RSUD Karawang were 68 patients, in female patients higher by $51.5 \%$ (35 patients) and rationality of therapy in GERD patients in RSUD Karawang using three literature namely Pharmacotherapy Handbook, British National Formulary edition 70 and GERD Consensus in the 2013 edition of Indonesia the average results were obtained: the exact indication was $80.4 \%$, the exact drug was $59.3 \%$, the exact patient was $89.7 \%$ and the exact dose was $64 \%$. In the bivariate analysis using the Kruskal Wallis analysis the $\mathrm{p}$ value of 0.014 indicates gender is a risk factor for signs and symptoms of Gastroesophageal Reflux Disease (GERD).
\end{abstract}

Keywords : Gastroesophageal Reflux Disease (GERD), Prevalence, Rationality of therapy, Outpatients. 


\section{PENDAHULUAN}

Gastroesophageal Reflux Disease (GERD) adalah suatu kondisi refluks HCL dari gaster ke esofagus, mengakibatkan gejala klinis dan komplikasi yang menurunkan kualitas hidup seseorang. GERD merupakan salah satu jenis gangguan pencernaan yang cukup sering dijumpai di masyarakat sehingga dapat menurunkan kualitas hidup (Ndraha, 2016).

Angka prevalensi GERD di Amarika Selatan yaitu 23,\%, Amerika Utara yaitu 18,1\%-27,8\%, Australia 11,6\%, Eropa yaitu 8,8\%-25,9\%, Asia Timur 2,5\%-7,8\% dan Indonesia didapatkan peningkatan prevalensi GERD dari 5,7\% pada tahun 1997 sampai 25,18\% pada tahun 2002 (El-Serag, 2014). Jenis kelamin laki-laki dan perempuan mempunyai risiko yang sama, hal ini terjadi akibat gejala GERD tidak mudah dibedakan dengan penyakit lambung lainnya sehingga perbedaannya harus lebih dicermati.

Ciri khas gejala utama dari timbulnya GERD jika pasien mengalami heartburn (rasa terbakar di dada yang kadang disertai rasa nyeri dan pedih) dan regurgitasi (rasa asam dan pahit di lidah) (Chaidir, 2013).

Perubahan gaya hidup berpengaruh terhadap stastus kesehatan, salah satunya adalah banyak tempat wisata kuliner yang tersebar diseluruh pelosok Kota Karawang. Disamping itu, kurangnya pengetahuan masyarakat dalam memahami timbulnnya gejala penyakit lambung menjadi salah satu penyebab meningkatnya angka pravalensinya di Indonesia yang terus meningkat setiap tahunnya didukung dengan aktivitas padat yang dapat memicu stress karena dapat menurunkan selera makan dan kadang membuat aktivitas makan meningkat. Atas dasar latar belakang itu, maka peneliti tertarik untuk meneliti pola penggunaan obat dan jenis terapi obat yang diberikan dengan judul Analisis Penggunaan Obat Gastroesophageal Reflux Disease (GERD) pada Pasien Rawat Jalan di Rumah Sakit Umum Daerah Karawang periode Januari-Desember 2018.

\section{METODE PENELITIAN}

Penelitian ini menggunakan rancangan penelitian analis kuantitatif untuk mengetahui angka kejadian, kerasionalan penggunaan obat dan faktor hubungan penyakit sedangkan kualitatif untuk mengetahui gambaran pola penggunaan obat 
dan karateristik pasien GERD dengan metode observasional. Data yang dikumpulkan adalah data sekunder berupa data rekam medik pasien rawat jalan yang terdiagnosis penyakit GERD periode bulan Januari-Desember 2018 di Rumah Sakit Umum Daerah Karawang.

Data yang diperoleh dari rekam medis dievaluasi kerasionalannya menggunakan tiga literatur Pharmacotherapy Handbook, British National Formulary edition 70 dan Konsensus GERD di Indonesia edisi tahun 2013, sedangkan untuk mengetahui pengaruh faktor jenis kelamin, umur dan penyakit penyerta dilakukan dengan uji statistik.

\section{HASIL DAN PEMBAHASAN}

Tabel 1.1 Karateristik Pasien GERD di RSUD Karawang

\begin{tabular}{lcc}
\hline \multicolumn{1}{c}{ Karateristik } & Frekuensi & Presentase (\%) \\
\hline Jenis Kelamin & 35 & 51,5 \\
Perempuan & 33 & 48,5 \\
Laki-laki & & \\
Usia & 18 & 26,4 \\
$18-40$ & 42 & 61,7 \\
$41-60$ & 9 & 13,2 \\
(61 & & \\
Penyakit Penyerta & 35 & 51,4 \\
GERD & 18 & 26,5 \\
GERD + CHF & 7 & 10,3 \\
GERD + Dispesia & 3 & 4,4 \\
GERD + Hipertensi & 1 & 1,5 \\
GERD + DM & 1 & 1,5 \\
GERD + Vertigo & 1 & 1,5 \\
GERD + Pneumonia & 1 & 1,5 \\
GERD + Anemia & & \\
Tanda dan Gejala & 30 & 44,1 \\
Nyeri ulu hati & 17 & 25 \\
Mual dan muntah & 13 & 19,1 \\
Lambung sakit & 8 & 11,8 \\
Sakit dada & & \\
\hline
\end{tabular}

Sampel yang digunakan semua populasi sebanyak 68 pasien. Pengambilan data menggunakan data sekunder yang diperoleh dari rekam medis pasien rawat jalan dewasa di Rumah Sakit Umum Daerah Karawang selama periode bulan JanuariDesember tahun 2018.

Berdasarkan hasil analisis dapat dilihat dalam tabel 1.1 bahwa mayoritas pasien Gastroesophageal Reflux Disease (GERD) adalah perempuan dengan jumlah 35 
pasien (51,5\%) dengan usia 41-60 tahun sebanyak 42 pasien (61,7\%). Berdasarkan kriteria penyakit penyerta lebih banyak pasien yang memiliki penyakit penyerta GERD dengan Congestive Herat Failure (CHF) sebanyak 18 pasien (26,5\%). Karateristik tanda dan gejala pasien Gastroesophageal Reflux Disease (GERD) Di RSUD Karawang yang paling banyak adalah nyeri ulu hati sebanyak 30 pasien $(44,1 \%)$.

Tabel 1.2 Karateristik Penggunaan Terapi Obat Pasien GERD Di RSUD Karawang

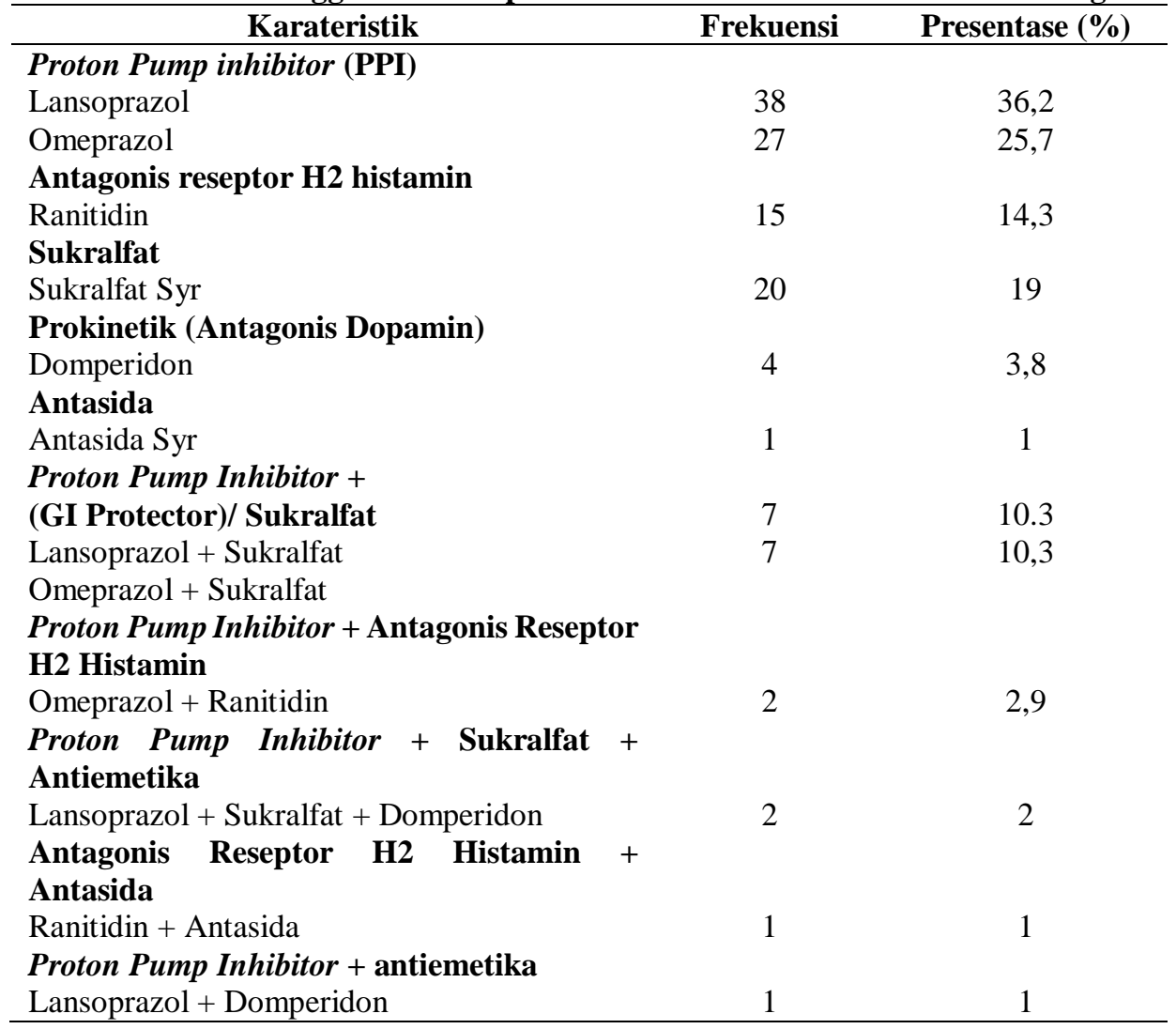

Berdasarkan hasil analisis dapat dilihat dalam tabel 1.2 bahwa terapi penggunaan obat Gastroesophageal Reflux Disease (GERD) di RSUD Karawang paling tinggi menggunakan golongan Proton Pump Inhibitor yaitu obat lansoprazol sebanyak 38 pasien $(36,2 \%)$ dan penggunaan terapi kombinasi obat Gastroesophageal Reflux Disease (GERD) di RSUD Karawang paling tinggi menggunaakan golongan obat Proton Pump Inhibitor dengan obat Sukralfat yaitu sebanyak 14 pasien (20,6\%).

Berdasarkan tabel 1.3 dibawah menunjukkan bahwa analisis kerasionalan penggunaan obat GERD di RSUD Karawang menggunakan literatur 
Pharmacoterpy Handbook eds 9, Konsensus GERD tahun 2013, BNF eds 70 diperoleh hasil rata-rata : tepat indikasi sebesar 80,4\%, tepat obat sebesar 59,3\%, tepat pasien sebesar $89,7 \%$ dan tepat dosis sebesar $64 \%$, dapat disimpulkan bahwa terapi pengobatan pasien GERD di RSUD Karawang sudah rasioanal.

Tabel 1.3 Kerasionalan Penggunaan Obat

\begin{tabular}{|c|c|c|c|c|}
\hline Ketepatan & $\begin{array}{l}\text { Pharmacoterpy } \\
\text { Handbook eds } 9\end{array}$ & $\begin{array}{c}\text { Konsensus } \\
\text { GERD } 2013 \\
\end{array}$ & $\begin{array}{c}\text { BNF } \\
\text { Eds 70 }\end{array}$ & Rata-rata \\
\hline \multicolumn{5}{|l|}{ Tepat } \\
\hline Indikasi & $68(100 \%)$ & $48(70,6 \%)$ & $48(70,6 \%)$ & $80,4 \%$ \\
\hline Tepat & $0(0 \%)$ & $20(29,4 \%)$ & $20(29,4 \%)$ & $58,8 \%$ \\
\hline \multicolumn{5}{|l|}{ Tidak } \\
\hline \multicolumn{5}{|l|}{ Tepat } \\
\hline \multicolumn{5}{|l|}{ Tepat } \\
\hline Obat & $41(60,3 \%)$ & $40(58,8 \%)$ & $40(58,8 \%)$ & $59,3 \%$ \\
\hline Tepat & $27(39,7 \%)$ & $28(41,2 \%)$ & $28(41,2 \%)$ & $42,7 \%$ \\
\hline \multicolumn{5}{|l|}{ Tidak } \\
\hline \multicolumn{5}{|l|}{ Tepat } \\
\hline \multicolumn{5}{|l|}{ Tepat } \\
\hline Pasien & $47(69,1 \%)$ & $68(100 \%)$ & $68(100 \%)$ & $89,7 \%$ \\
\hline Tepat & $21(30,9 \%)$ & $0(0 \%)$ & $0(0 \%)$ & $30,9 \%$ \\
\hline \multicolumn{5}{|l|}{ Tidak } \\
\hline \multicolumn{5}{|l|}{ Tepat } \\
\hline \multicolumn{5}{|l|}{ Tepat } \\
\hline Dosis & $45(66,2 \%)$ & $45(66,2 \%)$ & $40(58,8 \%)$ & $64 \%$ \\
\hline Tepat & $23(33,8 \%)$ & $23(33,8 \%)$ & $28(41,2 \%)$ & $36,3 \%$ \\
\hline \multicolumn{5}{|l|}{ Tidak } \\
\hline Tepat & & & & \\
\hline
\end{tabular}

Tabel 1.4. Faktor Perbedaan Jenis Kelamin, Umur dan Penyakit Penyerta Terhadap Tanda dan Gejala Pasien Menggunakan Uji Kruskal Wallis

\begin{tabular}{ccccc}
\hline & \multicolumn{2}{c}{ Uji Kruskal Wallis } & & \\
& \multicolumn{1}{c}{ Tanda dan gejala } & Frekuensi & Rata-rata & $\boldsymbol{p}$ value \\
\hline \multirow{3}{*}{ Jenis } & Nyeri ulu hati & 30 & 31,73 & \\
kelamin & Mual dan muntah & 17 & 31,00 & \\
& Lambung sakit & 8 & 29,75 & 0,014 \\
& Nyeri dada terasa panas & 13 & 48,38 & \\
Umur & Total & $\mathbf{6 8}$ & & \\
& Nyeri ulu hati & 30 & 39,23 & \\
& Mual dan muntah & 17 & 29,06 & \\
& Lambung sakit & 8 & 30,31 & \\
Penyakit & Nyeri dada terasa panas & 13 & 33,27 & \\
penyerta & Total & $\mathbf{6 8}$ & & \\
& Nyeri ulu hati & 30 & 35,27 & \\
& Mual dan muntah & 17 & 32,00 & \\
\hline
\end{tabular}


Berdasakan hasil analisis pada tabel 1.4 dapat dilihat pada analisis Kruskal Wallis nilain $p$ sebesar 0,014 menunjukkan jenis kelamin adalah faktor resiko tanda dan gejala Gastroesophageal Reflux Disease (GERD). Berdasarkan penelitian sebelumnya yang dilakukan oleh Nikko, (2018) "Prevalensi GERD ditemukan lebih tinggi pada jenis kelamin wanita dibanding pada laki-laki (53\% vs. 40\%,p >0,05)." Pada analisis Kruskal Wallis nilai $p$ sebesar 0,214 menunjukkan umur bukanlah faktor resiko tanda dan gejala Gastroesophageal Reflux Disease (GERD). Penelitian ini tidak sejalan dengan penelitian sebelumnya oleh Nikko, (2018) "Prevalensi GERD meningkat sesuai dengan usia ( $p$ value 0,059) dan juga meningkat sesuai BMI $(p>0,05)$." Pada analisis Kruskal Wallis nilai $p$ sebesar 0,481 menunjukkan penyakit penyerta bukanlah faktor resiko tanda dan gejala Gastroesophageal Reflux Disease (GERD). Penelitian ini tidak sejalan dengan penelitian sebelumnya oleh Nikko, (2018) "Bahwa prevalensi penyakit penyerta Gastroesophageal Reflux Disease (GERD) dengan Dispesia cukup tinggi karena faktor keadaan fisik dan makanan yang dapat menimbulkan gejala timbulnya penyakit. Selain itu, penyakit penyerta Gastroesophageal Reflux Disease (GERD) dengan Dispesia lebih banyak ditemukan pada pasien yang mengkonsumsi teh ( $p$ value 0,049$). "$

\section{PENUTUP}

\section{Kesimpulan}

Angka kejadian GERD di RSUD Karawang adalah 68 pasien, pada pasien perempuan lebih tinggi sebesar 51,5\% (35 pasien) sedangkan pada laki-laki sebanyak 48,5\% (33 pasien), pada usia pasien dewasa madya lebih tinggi 41-60 sebesar $61,7 \%$ (42 pasien). Kerasionalan terapi pada pasien GERD di RSUD Karawang menggunakan tiga literatur yaitu Pharmacotherapy Handbook, British National Formulary edition 70 dan Konsensus GERD di Indonesia edisi tahun 2013 diperoleh hasil rata-rata: tepat indikasi sebesar 80,4\%, tepat obat sebesar 59,3\%, tepat pasien sebesar $89,7 \%$ dan tepat dosis sebesar $64 \%$, dapat disimpulkan bahwa terapi pengobatan pasien GERD di RSUD Karawang sudah rasioanal. Faktor jenis kelamin dalam penelitian ini berpengaruh terhadap tanda dan gejala pasien GERD, sedangkan untuk Umur dan penyakit penyerta tidak berpengaruh atau bukan faktor resiko terhadap tanda dan gejala pasien GERD. 


\section{DAFTAR PUSTAKA}

Akmal, Faza. 2014. Sistem Pakar Untuk Mendiagnosa Penyakit Lambung Dengan Implementasi Metode Cbr (Case-Based Reasoning) Berbasis Web. Program Studi Teknik Informatika Universitas Ahmad Dahlan. Yogyakarta.

Alamsyah, Dedi Dan Ratna Mulia Wati. 2013. Pilar Dasar Ilmu Kesehatan Masyarakat. NuhaMedika. Yogyakarta.

British National Formulary 70. 2015. Gastrointestinal System. 32-83. London: BMJ Group and RPS Publishing.

Chaidir, Murnadi. 2013. Revisi Konsensus Nasional Penatalaksanaan Penyakit Refluks Gastroesofageal (Gastroesophageal Reflux Disease/GERD) di Indonesia. Pengurus Besar Perkumpulan Gastroenterologi Indonesia. Jakarta.

Dr. Asmarani. 2014. Ilustrasi Berwarna Anatomi \& Fisiologi. Jakarta.

Dipiro, 2015. Pharmacotherapy - A Pathophysiologic Approach 9th Ed. McGrawHill Education. London.

Junaedi. 2010. Ketentuan Uji Kruskal-Wallis. Jakarta Barat.

Katz PO, Gerson LB, Vela MF. 2013. Corrigendum: Guidelines for the diagnosis and management of gastroesophageal reflux disease. America.

Monica, Widi. 2017. Diagnosis dan Tatalaksana Gastroesophageal Reflux Disease (GERD) di Pusat Pelayanan Kesehatan Primer. Fakultas Kedokteran Universitas Tarumanagara. Jakarta Barat.

Naomi, Diah. 2014. Obesitas sebagai Faktor Risiko Penyakit Refluks Gastroesofageal Volume 3 Nomor 7. Jakarta.

Ndaraha, Suzunna. 2016. Faktor-Faktor yang Berhubungan dengan Keberhasilan Terapi GERD Volume 22 No. 60. Fakultas Kedokteran Universitas Kristen Krida Wacana (Ukrida). Jakarta Barat.

Nikko Darnindro, dkk. 2018. Prevalence of Gastroesophageal Reflux Disease (GERD) in Dyspepsia Patients in Primary Referral Hospital. Fatmawati General Hospital. Jakarta.

Nugraheni, Reny. 2015. Analisis Pelayanan Rekam Medis Di Rumah Sakit X Kediri Jawa Timur. Universitas Diponegoro. Jawa Timur.

Nursalam. 2007. Manajemen Keperawatan dan aplikasinya. Salemba Medika. Jakarta.

Peraturan Menteri Kesehatan Republik Indonesia No. 44 Tahun 2009, tentang Pengertian Rumah Sakit.

Peraturan Menteri Kesehatan Republik Indonesia No. 1197/Menkes/SK/X/2004 tentang Standar Pelayanan Farmasi di Rumah Sakit. 
Peraturan Menteri Kesehatan Republik Indonesia No.340 Tahun 2010, tentang Klasifikasi Rumah Sakit.

Peraturan Menteri Kesehatan Republik Indonesia No.72 Tahun 2016, tentang Standar Pelayanan Kefarmasian di Rumah Sakit.

Peraturan Menteri Kesehatan Republik Indonesia No. 560 Tahun 2003, tentang Pelayanan Pasien Rawat Jalan.

Peraturan Menteri Kesehatan Republik Indonesia No. 55 Tahun 2013, tentang Rekam Medis.

Peraturan Menteri Kesehatan Republik Indonesia N0. 269 Tahun 2008, tentang Rekam Medis.

Ridha Elvina, dkk. 2017. Evaluasi Penggunaan Obat Antimuntah Pada Pasien Anak Penderita Kanker Di Rumah Sakit Kanker Dharmais Jakarta Periode JuniJuli 2016. , Universitas Muhammadiyah Prof. Dr. Hamka. Jakarta.

Supranto, J. 2000. Teknik Sampling Untuk Survei dan Eksperimen. Jakata : Penerbit PT. Rineka Cipta.

Sharma PK, Ahuja V, Madan K, Gupta S, Raizada A, Sharma MP. 2010. Prevalence, severity, and risk factors of symptomatic gastroesophageal reflux disease among employees of a large hospital in Northern India. Indian.

Tim Penyusun Profil RSUD Karawang. 2013.

Tjay, T.H., Rahardja, K. 2002. Obat-obat Penting : Khasiat, Penggunaan, dan Efek-efek Sampingnya. Edisi VI. Jakarta : Penerbit PT. Elex Media Komputindo. 